\title{
Psychogenic vocal cord dysfunction simulating bronchial asthma
}

\author{
A. Mobeireek*, A. Alhamad + A. Al-Subaei+, A. Alzeer*
}

\begin{abstract}
Psychogenic vocal cord dysfunction simulating bronchial asthma. A. Mobeireek, A. Alhamad, A. Al-Subaei, A. Alzeer. CERS Journals Ltd 1995.

ABSTRACT: Upper airway obstruction can mimic bronchial asthma. A particular type results from psychogenic dysfunction of the vocal cord, and presents as bronchial asthma or organic upper airways obstruction. If not recognized, ineffective and potentially harmful therapy is given instead of focusing on the underlying psychopathology.

We report three Saudi females with this condition, in whom polygamy and a large family system created associated social stress. Spirometry with a flow-volume loop showed characteristic features, and in all three this test was the most important clinical tool that led to the correct diagnosis.

Clinicians should perform spirometry and flow-volume loop tests routinely in patients presenting with asthmatic symptoms, and look for clues suggestive of this condition, including a psychosocial assessment.
\end{abstract}

Eur Respir J., 1995, 8, 1978-1981
*Division of Pulmonology, and +Division of Psychiatry, Dept of Medicine, College of Medicine, King Saud University, Riyadh, Saudi Arabia.

Correspondence: A. Mobeireek,

P.O. Box 52179

Riyadh

Saudi Arabia

Keywords: Asthma

conversion disorder

polygamy

spirometry

vocal cord

Received: April 101995

Accepted after revision July 131995
Vocal cord dysfunction secondary to psychogenic factors (PVCD) was first recognized in 1974, presenting as organic upper airways obstruction [1]. Presentations with a picture simulating bronchial asthma were later described. A recent review summarized 48 cases found in the English language literature [2]. Interest in this condition is focused both on features that may help in its recognition and, therefore, avoid the serious consequences resulting from misdiagnosis, and on the underlying psychodynamics. We report, for the first time to our knowledge, three patients from the Middle East region, and discuss the relevance of cultural stresses and diagnostic clues, particularly the flowvolume loop.

\section{Case reports}

\section{Case No. 1}

A 40 year old woman was admitted to hospital with moderate and severe attacks of bronchial asthma on eight occasions between 1988 and 1992. She was first labelled asthmatic after admission to another hospital in Riyadh in 1986. These attacks were characterized by dyspnoea, cough and wheeze, with no clear precipitating factors, except on two of her admissions where a history of a flu-like illness was given. There was no history of other atopic disorders and no family history of asthma.

On examination, the patient was tachypnoeic and tachycardic, and diffuse inspiratory and expiratory rhonchi were heard. Multiple investigations were performed including full and differential blood counts, chest roentgenography, computed tomography of the chest and electrcardiography which revealed no abnormality. Initial arterial oxygen tension $\left(\mathrm{Pa}_{\mathrm{a}} \mathrm{O}_{2}\right)$ ranged $7.9-8.4 \mathrm{kPa}$ and arterial carbon dioxide tension $\left(\mathrm{Pa}_{\mathrm{a}} \mathrm{CO}_{2}\right)$ was in the normal range, except during her two intensive care admissions when she developed $\mathrm{CO}_{2}$ retention with acidosis. She was refractory to high dose parenteral corticosteroids.

Peak expiratory flow rate values were erratic. Spirometric values in 1991 were: forced expiratory volume in one second (FEV1): $1.5 \mathrm{~L}$ (62\% of predicted); forced vital capacity (FVC) $1.6 \mathrm{~L}$ (55\% pred); and maximum expiratory flow at $50 \%$ of vital capacity (MEF50) 2.4 $\mathrm{L} \cdot \mathrm{s}^{-1}$ (55\% pred). In 1992, values were: FEV1 $2.3 \mathrm{~L}$ (92\% pred); FVC: $2.6 \mathrm{~L}$ (86\% pred), and MEF50 $4.2 \mathrm{~L} \cdot \mathrm{s}^{-1}$ (94\% pred). There was no significant change in these values after giving a bronchodilator. Inspiratory flows were reduced on both occasions, and the flow-volume loop was consistent with extrathoracic upper airways obstruction (fig. 1a).

Noticing this abnormality, elective bronchoscopy was planned to rule out upper airways obstruction. The patient developed severe dyspnoea and wheezes just after local anaesthesia with xylocaine, leading to her eighth hospital admission. Laryngoscopy revealed abnormal adduction of her vocal cords on inspiration. Motion of the vocal cords normalized with the onset of action of diazepam, that was given as a sedative. Furthermore, when asleep, her breathing was quieter and she appeared more comfortable. Steroids and bronchodilators were discontinued uneventfully. 
a) Case No. 1

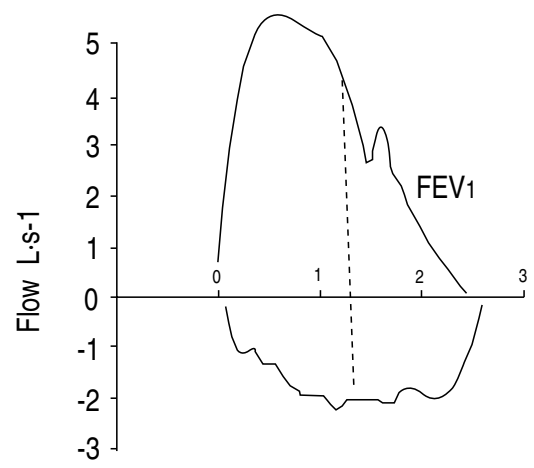

b) Case No. 2

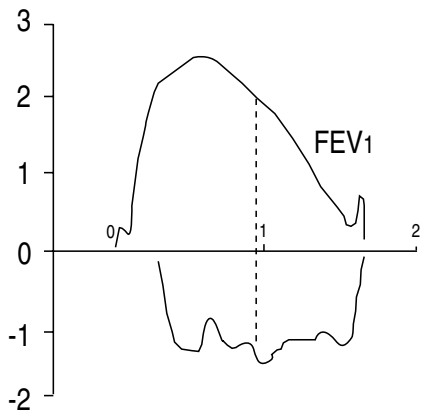

c) Case No. 3

Volume L

Fig. 1. - Flow-volume loops. Maximum inspiratory and expiratory curves in the three patients. The dotted lines represent flows at $50 \%$ of vital capacity (MEF: MIF). This was over 1.5 in all three. FEV1: forced expiratory volume in one second.

The patient was educated about the nature of her breathing difficulty, taught breathing exercises (as described by MARTIN et al. [3]), and had an improvement in her pulmonary symptoms. She declined to undergo bronchial challenge testing with methacholine.

Psychiatric evaluation. This lady was a housewife and a mother of nine children (aged 9 to $26 \mathrm{yrs}$ ). She was the first wife of a 55 year old man. Her pulmonary condition started 8 yrs after the marriage of her husband to a younger woman, who then moved to live in the same house. The patient was unable to express her anger and resentment towards her husband and his other wife, and would not even allow herself the right to complain. Her asthma-like attacks could be temporally related to stressful events resulting from confrontations with her husband's other wife. Her illness provided her with some secondary gain of love and care that might not otherwise be forthcoming. She therefore probably had a conversion disorder.

Focusing on supportive psychotherapy was enough to obtain an improvement in her condition. She also had some dysthymic features. She received supportive psychotherapy and doxepin (Sinequan ${ }^{\circledR}$ ) $100 \mathrm{mg}$ o.d. She was followed up as an out-patient for 3 yrs, with improvement in her psychological and physical well being and no further attacks.

\section{Case No. 2}

Review of documents of this 24 year old female at two hospitals revealed that she was admitted seven times for asthma, tracheobronchitis and stridor. Her symptoms included cough, dyspnoea and wheeze. The patient denied any specific or nonspecific triggers for her symptoms. There was no history of other allergic disorders and no family history of atopy.

Physical examination during these admissions revealed inspiratory and expiratory wheeze or inspiratory stridor, although she never appeared in severe respiratory distress. Full and differential blood counts and chest roent- genogram were normal. Arterial blood gases showed mild hyperventilation and normal oxygenation. The patient had bronchoscopy and two laryngoscopies that revealed no abnormalities apart from mild laryngeal oedema on one occasion. Spirometry showed reduction in FEV1 to 1.2 $\mathrm{L}$ (43\% pred) and FVC to $1.2 \mathrm{~L}$ (37\% pred), probably reflecting poor effort. No flow-volume loop was available. She had poor response to steroids, bronchodilators and antibiotics.

On her seventh admission, spirometry and a flowvolume loop were performed, which showed the following values: FEV1 $2.7 \mathrm{~L}$ (56\% pred); FVC 1.7L (51\% pred) and MEF50: $2.1 \mathrm{~L} \cdot \mathrm{s}^{-1}(47 \%$ pred), with no significant change after giving a bronchodilator. The flowvolume loop showed an abnormality similar to the first patient (fig. 1b). Abnormal vocal cord adduction during inspiration was again observed on laryngoscopy. She did not consent for bronchial challenge tests.

The patient was educated, counselled and received speech therapy and breathing exercises [3]. Her respiratory symptoms settled and steroids and bronchodilators were discontinued, again uneventfully. A psychiatric consultation was obtained but she did not come for follow-up. She had one more admission 3 months later for suspected deep vein thrombosis, after presenting with lower limb oedema. This proved to be self-induced after she was discovered to tie her thighs secretly.

Psychiatric evaluation. During the first interview, the patient was uncooperative and denied having any present or previous psychiatric problems. An informant account gave a history of various psychological disturbances in the preceding $7 \mathrm{yrs}$. She had a history of a conversion disorder when she lost her vision for 6 months at the age of 16 yrs. During the preceding 4 yrs, she had excessive hair loss and generalized skin itching, for which no organic cause was found. She had laparoscopy for abdominal pain and the wound never healed properly, raising the suspicion of self-inflicted trauma. On the last admission, she was noticed to induce leg oedema by tying her thighs. 
The patient married at the age of $14 \mathrm{yrs}$ for $1 \mathrm{yr}$, and was then divorced to remarry again as a second wife, which added considerable stress to her life. During that period, her respiratory symptoms became prominent. She was diagnosed to have a factitious disorder, probably Münchhausen syndrome. An underlying personality disorder was suspected, but psychological testing could not be performed due to a lack of cooperation. Psychotherapy sessions were started, but the patient was reluctant to receive any further psychiatric help.

\section{Case No. 3}

This 16 year old girl reported intermittent dysponea, cough, and wheeze for 6 years, with no clear precipitating factors. There was no history of other allergic disorders and no family history of atopy. She was admitted nearly 20 times to a local hospital for presumed asthmatic attacks and received frequent courses of corticosteroids.

On examination, she had inspiratory and expiratory wheezes that were louder in the neck. She also had stiae in all extremities. No previous spirometry was available. Investigations, including full and differential blood counts, chest roentgenogram and arterial blood gases, were within normal limits. Peak expiratory flow rate values were again erratic. Immunoglobulin $\mathrm{E}$ was slightly elevated to $371 \mathrm{U} \cdot \mathrm{mL}^{-1}$. Skin testing for common allergens showed intermediate reaction to house dust mite only. Spirometric values were: FEV1 3.3 L (117\% pred); FVC: 3.3 L (107\% pred); and MEF50 $4.5 \mathrm{~L} \cdot \mathrm{s}^{-1}$ (103\% pred) with no significant change after giving bronchodilator. Two other sets of measurements at intervals and when symptomatic were similar. The flow-volume loop, however, and laryngoscopy showed abnormalities similar to the first two patients (fig. 1c). On bronchial challenge with methacholine, the provocative concentration required to achieve a $20 \%$ reduction in FEV1 was $0.16 \mathrm{mg} \cdot \mathrm{mL}^{-1}$. In hospital she had repeated at-acks of hyperventilation during which her wheezes disappeared.

After explanation and reassurance her respiratory symptoms were no longer her main focus and she remained off systemic corticosteroids. On a later follow up, she complained of troublesome abdominal pain, but no objective findings were documented.

Psychiatric assessment. This patient was a daughter of a second wife and lived with her parents, stepmother and 17 full and half siblings in one house. She was not educated or employed, and had to look after her blind grandfather with whom she had a close relationship. She was also overloaded with housework while other family members went to school or work. She had depressive symptoms with multiple somatic complaints that got worse after the loss of her grandfather one year earlier. She had poor awareness of her inner conflicts and the illness provided her with secondary gain of care and attention by her parents and relieved her from household chores. She resisted going home and after discharge came back with a drug overdose. It seems that the sheltered hospital environment symbolized her protective grandfather care. She was treated with psychotherapy and antidepressants and is still under follow up.

\section{Discussion}

All the patients were females, which is typical of this condition [2], and all presented asthma-like attacks of different severities requiring several admissions. They received significant dosage of corticosteroids, and in the first patient cytotoxic drugs were being considered for an apparent corticosteroid resistance.

A multitude of psychopathological abnormalities and social stresses were present, but the relation to the presenting physical symptoms was overlooked. Somatization is a common way of help seeking among Saudi women [4]. Also, conversion disorder, another typical association with psychogenic vocal cord dysfunction [2], is one of the commonest psychiatric disorders in Saudi Arabia [5]. In our patients polygamy and large family system seemed to have increased their sensitivity to the discord which is endemic in such families [6]. Such stresses resulted in conscious or unconscious production and substitution of physical symptoms. Primary gain diverted internal conflicts or needs into physical symptoms, thereby avoiding anxiety resulting from surfacing of the conflict to awareness. Secondary gain on the other hand provided them with support, attention and sympathy.

The flow-volume loops, performed during an attack, with a maximum expiratory and inspiratory manoeuvre showed a plateau in the inspiratory limb (because of reduction in inspiratory flow) resulting in increased maximum expiratory flow to maximum inspiratory flow at $50 \%$ of vital capacity (MEF:MIF) ratio [7]. Also, the typical features of asthma such as the reduced and prolonged expiratory flows and the improvement after giving a bronchodilator were absent. Another finding in all the patients, not reported in association with this condition to our knowledge but observed in certain forms of upper airway obstruction [7], is "sawtoothing" or fluttering of the inspiratory limb. This may be a reflection of disturbed flow related to the abnormal cord movement. The flowvolume loop was the most important clinical tool that led to doubts about the original diagnosis of asthma in all the patients. In the review by LACY and MCMANIS [2], suggestive clues were present in all the patients who performed this test.

Other clues should rise the clinical suspicion. Our patients had erratic peak expiratory flow rates (PEFR) values with loss of the circadian rhythm, and appeared well when asleep or distracted. In most of the reported cases there was no evidence to suggest atopy or bronchial hyperresponsiveness. In a few, however, co-existing asthma was observed [8]. This was also possible in our third patient. Multiple spirometric measurements and flow-volume loops showed that her symptoms were out of proportion. A normal alveolar to arterial (A-a) gradient is an additional clue [9]. However, hypoxia can occur in severe cases, as was evident in our first case and in a few other reported cases $[10,11]$, and its presence does not rule out this condition. Visualization of the 
vocal cord movement during the attack by laryngoscopy remains the definitive test. This was done three times in the second lady but the abnormality was not observed. This could be due to prior sedation before this procedure, or performing it after the attack had settled. In the latter situation certain manoeuvres may help to provoke the abnormal movement [3].

The long term outcome of this condition is unknown, because our knowledge is based on case reports with short follow up. In many cases the initial response to speech therapy, breathing exercises and psychotherapy is good. This was true of our first patient. The second continued to develop other factious disorders, whilst the third is still undergoing follow-up. It is likely that the prognosis is related to the nature and severity of underlying psychopathology.

Clinicians should always keep in mind that upper airway obstruction may mimic bronchial asthma and recognize this type in patients with suggestive clues. The use of spirometry with a flow-volume loop during the attack is simple, inexpensive, and diagnostic. We also concur with previous authors [9-11], that suspected cases should be treated as bronchial asthma until the diagnosis is confirmed. Finally, physicians are reminded of the need for a careful assessment of the psychosocial setting.

Acknowledgements: The authors wish to thank F. Kassim for reviewing the manuscript and O. Gurrea for secretarial assistance.

\section{References}

1. Patterson R, Schatz M, Horton M. Munchausen's stridor: nonorganic laryngeal obstruction. Clin Allergy 1974; 4: 307-310.

2. Lacy TJ, McManis SE. Psychogenic stridor. Gen Hosp Psychiatry 1994; 16: 3: 213-223.

3. Martin RJ, Blager FB, Gay ML, Wood II, RP. Paradoxic vocal cord motion in presumed asthmatic. Semin Respir Med 1987; 8: 332-337.

4. Racy J. Somatization in Saudi women: a therapeutic challenge. Br J Psychiatry 1980; 137: 212-216.

5. Al-Subaie A. Psychiatry in Saudi Arabia: Cultural perspectives. Transcult Psychiatr Res Rev 1989; 26: 145252.

6. Chaleby K. Psychosocial stresses and psychiatric disorder in an out patient population in Saudi Arabia. Acta Psychiatr Scand 1986; 73: 147-151.

7. Miller A. Inspiratory flows and flow-volume loops in the diagnosis of upper airway obstruction. In: Miller A, ed. Pulmonary Function Testing in Clinical and Occupation Lung Disease. Orlando, Grune and Stratton Inc, 1986; 53-65.

8. Sette L, Pajno-Ferrara F, Mocella S, Portuese A, Boner AL. Vocal cord dysfunction in asthmatic child: case report. J Asthma 1993; 30: 407-412.

9. Goldman J, Muers M. Vocal cord dysfunction and wheezing (Editorial). Thorax 1991; 46: 401-404.

10. Nolan MT, Gibney N, Brennan N, Fitzgerald MX. Paradoxical vocal cord motion asthma. Thorax 1985; 40: 689.

11. Niven R McL, Roberts T, Pickering CAC, Web AK. Functional upper airways obstruction presenting as asthma. Respir Med 1992; 86: 513-516. 